\title{
Effects of association and repetition in memory for temporal order*
}

\author{
ROBERT W. PROCTOR $\dagger$ \\ University of Texas, Arlington, Texas 76010 \\ and \\ JOE L. LEWIS \\ University of Washington, Seattle, Washington 98105
}

\begin{abstract}
Temporal order recognition memory has been examined previously with tasks involving a recency judgment between a pair of items in a preceding string. Recency judgments are impaired when the earlier item is repeated. The present study employed the comparative recency judgment paradigm, with the lists composed of words. The effect of the inclusion in the list of a high associate of the earlier test item was examined and compared to the effect of repetition. Associative interference was observed, but not in all conditions. Direction of association was a significant factor. The results were interpreted in terms of a model of word recognition proposed by Morton.
\end{abstract}

One important aspect of memory involves temporal information. Temporal information is important in order to recognize how recently an event occurred and whether one event preceded or followed another.

Several studies have previously examined judgments of recency and the factors that influence them. Yntema and Trask (1963) used the procedure requiring the $S$ to make a comparative judgment of which of two items occurred more recently (closer to the end) in a list. They found that accuracy of judgment decreased as the number of items intervening between the more recent of the test items and recall increased. Accuracy also decreased as the separation of the two test items in the list was reduced.

Morton (1968a), using a similar procedure, examined the effect of repeating the earlier of the two test items in the list. He found that performance in choosing the more recent test item was impaired when the earlier item was repeated, compared to the case when the earlier item was not repeated.

The results of both studies are in accord with trace-strength theories of memory in general and with a model of word recognition and production proposed by Morton $(1968 \mathrm{~b}, 1969,1970)$ in particular. The model has as its main feature a set of "logogens," which are devices that accept information relevant to a particular word. When the number of occurring members in its

*Supported by the Liberal Arts Organized Research Fund, University of Texas at Arlington. The present study was based upon a MA thesis by Robert Proctor under Joe L. Lewis. The authors would like to thank Ira H. Bernstein and Duane R. Martin for assistance at all stages of the research and Charles Smith for gathering the data in Experiment II. A portion of these data were presented at the 1973 convention of the Southwestern Psychological Association, Dallas, Texas.

$\nmid$ Requests for reprints should be addressed to Robert W. Proctor, Department of Psychology, University of Texas, Arlington, Texas 76010 . defining set exceeds a threshold level, a response is made available to an output buffer. Following the availability of a response, the threshold of the logogen is lowered and returns to a value slightly less than the original over a relatively long period of time.

Peterson, Johnson, and Coatney (1969) used a slightly different paradigm in which Ss were asked to make absolute judgments of the number of items that intervened between the occurrence of a particular item and the end of the list. When the tested item was repeated, there was a decrease in the number of items thought to have followed the second occurrence of it in the list, but only when there were no intervening items between the occurrences of the tested item. One interpretation of their results is that Ss form a single trace when there are no intervening items between the two occurrences but form two separate traces when items intervene. ${ }^{1}$ Because Morton used only one intervening item between repetitions, it is possible that the small effect he obtained was due to the Ss forming a single trace on some trials. If such was the case, Morton's results would not generalize to conditions with more intervening items, and the single-trace notion of his model would not be supported.

A second major feature of the model is the cognitive system. Material in it is coded in a semantic form. This system is responsible for associational phenomena that occur in a task. Upon recognition of a stimulus, information about it is transferred from the logogen to the cognitive system. The cognitive system then sends information back to the logogen system, boosting the strength of the particular logogen and, to a lesser extent, associated logogens in proportion to the strength of the associative relationship.

One implication of Morton's model is that judgments of recency should be impaired by the inclusion in the list of an associate of the less recent test item. The 
Table 1

Critical Word Positions for Each Type of Experimental Trial*

\begin{tabular}{|c|c|c|c|c|c|c|c|c|c|c|c|c|c|c|c|c|c|}
\hline & & \multicolumn{16}{|c|}{ Position in List } \\
\hline & & 1 & 2 & 3 & 4 & 5 & 6 & 7 & 8 & 9 & 10 & 11 & 12 & 13 & 14 & 15 & 16 \\
\hline Condition S-8 & $\begin{array}{l}\mathrm{a} \\
\mathrm{b} \\
\mathrm{c} \\
\mathrm{d}\end{array}$ & & B & & B & & B & & $\begin{array}{l}\text { B } \\
\text { B } \\
\text { B } \\
\text { B }\end{array}$ & & $\begin{array}{l}\mathbf{A} \\
\mathbf{A} \\
\mathbf{A} \\
\mathbf{A}\end{array}$ & & & & & & \\
\hline Condition A-8 & $\begin{array}{l}\mathrm{a} \\
\mathrm{b} \\
\mathrm{c} \\
\mathrm{d}\end{array}$ & & $\mathrm{B}^{\prime}$ & & $\mathrm{B}^{\prime}$ & & $\mathrm{B}^{\prime}$ & & $\begin{array}{l}\text { B } \\
\text { B } \\
\text { B } \\
\text { B }\end{array}$ & & $\begin{array}{l}\text { A } \\
\text { A } \\
\text { A } \\
\text { A }\end{array}$ & & & & & & \\
\hline Condition A-V & $\begin{array}{l}\mathrm{a} \\
\mathrm{b} \\
\mathrm{c} \\
\mathrm{d}\end{array}$ & & B & & B & & B & & $\begin{array}{l}\mathrm{B} \\
\mathrm{B}^{\prime} \\
\mathrm{B}^{\prime} \\
\mathrm{B}^{\prime}\end{array}$ & & $\begin{array}{l}\mathbf{A} \\
\mathbf{A} \\
\mathbf{A} \\
\mathbf{A}\end{array}$ & & & & & & \\
\hline Condition $\mathrm{N}-\mathrm{V}$ & $\begin{array}{l}\mathrm{a} \\
\mathrm{b} \\
\mathrm{c} \\
\mathrm{d}\end{array}$ & & B & & B & & B & & $\begin{array}{l}\text { B } \\
\text { C } \\
\text { C } \\
\text { C }\end{array}$ & & $\begin{array}{l}\mathbf{A} \\
\mathrm{A} \\
\mathrm{A} \\
\mathrm{A}\end{array}$ & & & & & & \\
\hline
\end{tabular}

${ }^{*} A=$ most recent word presented for recency test; $B=$ least recent word presented for recency test; $B^{\prime}=\dot{a}$ semantically related high associate of $B ; C=a$ word not related to $B$.

impairment should be similar to but of less magn than that found when the earlier test item is repeate.. One aim of the present study was to examine effects of association in relation to Morton's model.

In summary, the present studies were designed (1) to replicate Morton's (1968a) repetition results, (2) to examine the effect of the inclusion in the list of an associate of the less recent test item, (3) to compare the effects of association and repetition, and (4) to explore the effects of position in the list of the less recent test item and its repetition or associate.

\section{EXPERIMENT I}

Method

\section{Subjects}

Sixty-four students enrolled in an introductory psychology course at the University of Texas at Arlington were used as Ss. Sixteen Ss were used in each condition. All Ss received experimental credit toward course requirement for participating. The only restrictions in soliciting Ss were that they be native English speakers and that they have normal hearing.

\section{Design and Stimuli}

Stimuli consisted of lists of 16 single-syllable nouns recorded on a magnetic tape at a presentation rate of one word per second. The lists were presented binaurally by a ReVox A77 tape recorder through Realistic ST-28 headphones. Following the list, two of the words from the list were presented visually for a recency judgment. The two test words were mounted on slides and rear-projected through a ground glass screen by a Kodak $750 \mathrm{H}$ slide projector. The Ss performance was monitored by the $\mathrm{E}$ in an adjoining room using the amplifier of a Sony TC-366 tape recorder.
Each S was randomly assigned to one of four conditions (see Table 1). Conditions were similar in that, in the experimental trials, the more recent of the two words presented for the recency judgment always occurred in Position 10 . The less recent word occurred in at least one of the following positions: $8,6,4$, and 2. One-fourth of the trials in each condition were exactly the same for all conditions (see Table 1): Recency judgments were made between the words occurring in Positions 8 and 10 . The remaining trials were different for each condition. In Condition S-8 (same word, less recent test item in Position 8), the recency judgments were made between the two words occurring in Positions 8 and 10. However, the less recent test item was also presented (repeated) equally of ten in Position 2, 4, or 6. Condition A-8 (Associate-Position 8) was the same as Condition S-8, with the exception that the words occurring in Positions 2, 4, or 6 were associatively related to the word in Position 8 rather than being the same word. Condition $\mathrm{A}-\mathrm{V}$ (associate-variable test) was exactly the same as Condition A-8 in that the words in Positions 2, 4, or 6 were associatively related to the words in Position 8. The only difference was that the words used as test items were the associates occurring in Positions 2,4 , or 6 rather than the words occurring in Position 8 . Condition N-V (nonrelated-variable test) was exactly the same as Condition A-V, except that the words in Position 8 were not related to the test items in Positions 2, 4, or 6. The associate pairs used in both Conditions A-8 and A-V were semantically related nonsynonym nouns of high associative strength taken from the Minnesota Association Norms (Palermo \& Jenkins, 1964; frequencies greater than or equal to 38) and the Connecticut Free Associational Norms (Bousfield, Cohen, Whitmarsh, \& Kincaid, 1961; frequencies greater than or equal to 10 ). The stimulus member of each associate pair, rather than the response member, was the tested item in both Condition A-8 and Condition A-V. All members of test pairs were equated for frequency of occurrence in the English language according to the frequency norms of Kucera and Francis (1967). A Latin-square design (Winer, 1971) was used so that every critical word pair (repetitions, associates) occurred in all four positions.

In addition to the experimental trials, an equal number of control trials were presented each session. For these trials, the 
Table 2

Experiment I: Mean Percent Correct Data for Conditions S-8 and A-8

\begin{tabular}{lcccccc}
\hline & \multicolumn{2}{c}{ Position of Word Related to Less Recent Test Item } & & \multicolumn{1}{c}{ Mean } \\
\cline { 2 - 5 } Condition & 6 & 4 & 2 & $\mathrm{~N}$ & $(\mathrm{~N}, 2,4,6)$ \\
\hline S-8 & 46.87 & 46.70 & 52.22 & 61.65 & 51.86 \\
A-8 & 60.80 & 57.10 & 63.07 & 63.41 & 61.09 \\
Mean & 53.93 & 51.90 & 57.68 & 62.52 & 68.60 \\
\hline
\end{tabular}

Table 3

Experiment I: Mean Percent Correct Data for Conditions A-V and N-V

\begin{tabular}{lcccccc} 
& \multicolumn{4}{c}{ Position of Less } & Recent Test Item & \multicolumn{2}{c}{ Mean } \\
\cline { 2 - 6 } Condition & 2 & 4 & 6 & $\mathrm{~N}$ & $(\mathrm{~N}, 2,4,6)$ \\
\hline A-V & 68.75 & 65.11 & 62.05 & 63.52 & 64.86 \\
N-V & 76.59 & 75.45 & 64.37 & 60.23 & 71.66 \\
Mean & 72.67 & 70.28 & 63.21 & 61.85 & 65.29 \\
\hline
\end{tabular}

position in the list of the two words presented for the recency judgment was varied in a selected sample of all positions so that all positions were represented equally often. The control trials were exactly the same for all conditions, with the exception that in Condition S-8 one-fourth of the control trials had a randomly chosen nontest item that was repeated once. Four randomizations of trials were used, with the only restriction being that no more than three trials of either type, experimental or control, could occur in a row. The result was a 16 (Ss) by 4 (conditions) by 4 (positions) design, with repeated measures on positions.

\section{Procedure}

The experimental sessions lasted approximately $1 \mathrm{~h}$. Ninety-six trials, 48 experimental trials, and 48 control trials were presented each session. Each trial commenced with a warning signal of three clicks presented through the headphones. The clicks were followed by a list of 16 words for the $S$ to shadow. Immediately following the list, the $\mathrm{S}$ was shown visually two of the words that appeared in the list. His task was to state

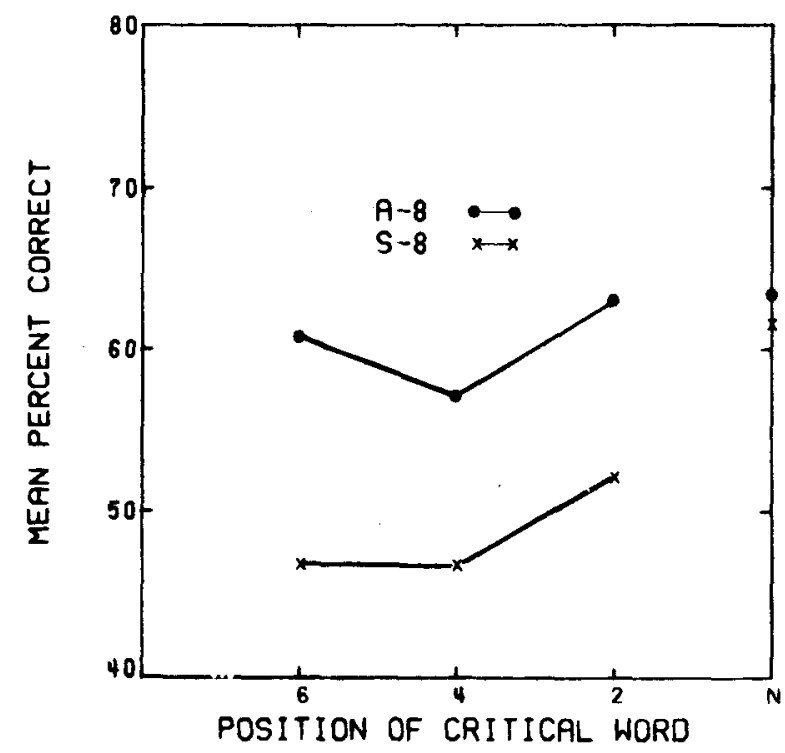

Fig. 1. Mean percent correct recency judgments as a function of position in list and type of relation (same, associate) of word related to less recent test item. which of the two words occurred more recently (later) in the list. Approximately $35 \mathrm{sec}$ elapsed between the start of one trial and the start of the next. At the beginning of the session, the $S$ was given instructions indicating the general nature of the task. Eight training trials were then presented. The Ss had to reach a criterion of correctly shadowing three of the last four lists. No $S$ failed to reach criterion. The $\mathrm{Ss}$ were given a 5 -min break midway through the session.

\section{Results}

The mean percent correct data for Experiment I are shown in Tables 2 and 3 and Figs. 1 and 2. The percent correct data was transformed by a square-root transformation for the purpose of analysis because of the proportionality between the means and the variances (Winer, 1971). Conditions S-8 and A-8 and Conditions $\mathrm{A} \cdot \mathrm{V}$ and $\mathrm{N} \cdot \mathrm{V}$ were analyzed separately. ${ }^{2}$ An analysis of variance of all four conditions would have no meaning, since in Conditions S-8 and A-8 the position of the least recent test item was held constant, while in Conditions $\mathrm{A}-\mathrm{V}$ and $\mathrm{N}-\mathrm{V}$ the position of the least recent test item was varied.

A $t$ test comparing Position $\mathrm{N}$ from Conditions $\mathrm{S}-8$ and A-8 indicated no significant difference in the base-rate performance $(t=.494)$. A two-factor analysis of variance of Conditions (S-8, A-8) by Positions $(2,4$, 6 ) indicated only a significant conditions main effect [conditions $(C): F(1,30)=15.319, p<.01]$. Neither the $\mathrm{P}$ main effect nor the $\mathrm{C}$ by $\mathrm{P}$ interaction was significant $[P: F(2,60)=2.166, p<.25 ; C$ by $P: F(2,60)=.259]$. The means (see Table 2 and Fig. 1) indicate that the $\mathrm{C}$ main effect is due to the percent correct being less when the earlier test word is repeated $(48.60 \%)$ than when an associate of it is in the list $(60.32 \%)$.

For both conditions, Wilcoxon matched-pairs tests were run on each position $(6,4$, and 2$)$ against the control (Position N). For Condition S-8, a significant effect was found for Positions 6 and 4 [P-6: $z=2.11$, $p<.025 ; P-4: z=2.20, p<.025]$. Position 2 just failed to attain significance $(z=1.50, p<.075)$. For Condition A-8, no position was significantly different 


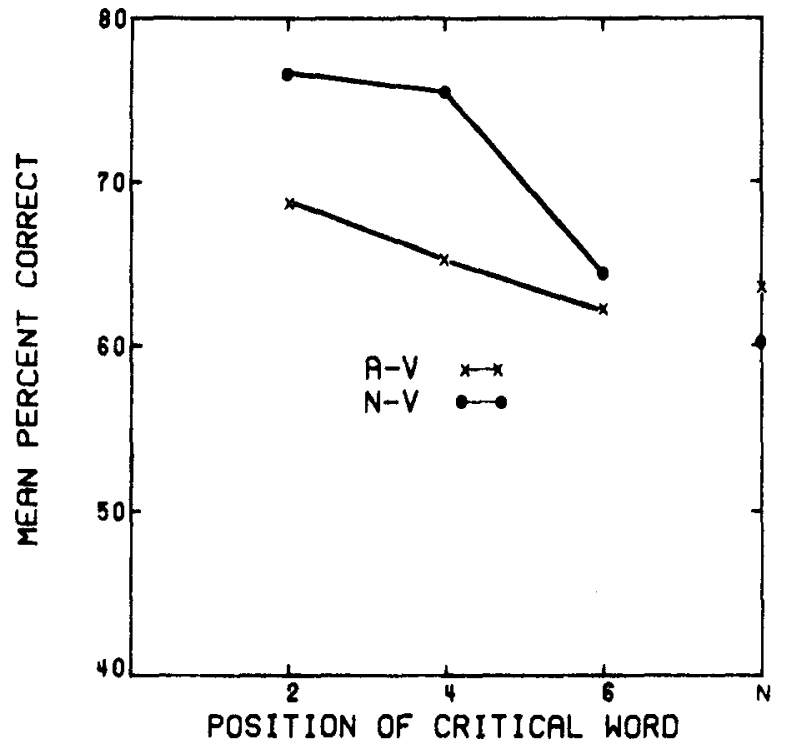

Fig. 2. Mean percent correct recency judgments as a function of position of less recent test item and associate vs no associate in the list.

from the control $[\mathrm{P}-6: \mathrm{z}=.046 ; \mathrm{P}-4: \mathrm{z}=1.32 ; \mathrm{P}-2$ : $\mathrm{z}=.051]$.

A $t$ test comparing Position $\mathrm{N}$ from Conditions $\mathrm{A}-\mathrm{V}$ and $\mathrm{N}-\mathrm{V}$ indicated no significant difference in base-rate performance $(t=.82)$. A two-factor analysis of variance of conditions (A-V, N-V) by Positions $(2,4,6)$ indicated significant effects for both main effects [C: $F(1,30)=4.295, p<.05 ; P: F(2,60)=3.534, p<.05]$. The $C$ by $P$ interaction was not significant $[F(2,60)=.467]$. The means (see Table 3 and Fig. 2) indicate that the $C$ main effect is due to percent correct being less when there is an associate of the least recent test item in the list $(65.29 \%)$ than when there is no associate of it in the list $(72.14 \%)$. The $P$ main effect is due to percent correct being greater as the number of intervening items between the two test words increases. When the test items are separated by one word (Position 8) mean percent correct is $61.85 \%$; three words (P-6), 63.21\%; five words (P-4), 70.28\%; and seven words (P-2), $72.67 \%$.

\section{Discussion}

The results confirm Morton's (1968a) finding that Ss accuracy in making comparative recency judgments is impaired when the earlier word is repeated. The effect is found whether there are one or several items intervening between the two occurrences.

The results of repetition employing the comparative judgment task contradict the results obtained by Peterson et al (1969) with the absolute judgment task. In contrast with the lack of effect found by Peterson et al, strong effects of repetition are obtained in the present study when items intervene between the two occurrences of the repeated word. Several procedural differences could possibly account for the difference, but the most probable explanation is that the comparative judgment, as shown in many other tasks, is more sensitive than absolute judgment.

Two differences between Morton's study and the present one are of interest. Morton's Ss performed at approximately chance level $(51.7 \%)$ when neither test digit was repeated, while in the present study none of the mean percent correct scores for any similar condition were below $60 \%$. The difference is likely due to the greater confusability that results from the repetition of the small set of digits on every trial as compared to the large number of words used in the present study.

A second difference in the two experiments is the extent of the repetition effect. Morton found only a 5\% decrease in percent correct, while in the present study the decrease was approximately $15 \%$ when there were three or one intervening items (as in Morton's study) and approximately $9.5 \%$ when there were five intervening items. Again, the most probable explanation lies in the digit-word difference. The usage of the same digits every trial may have raised the traces or, in terms of Morton's model, lowered the thresholds to such a level that the repetition of an item in the list had little effect in comparison. The chance-level performance mentioned previously would seem to support this contention.

According to Morton's model, when a $S$ judges an item in memory he should not be able to tell whether an item was heard once or twice. The strength of the logogen is the only index by which he has to judge. In informal postexperimental discussions with the Ss who had participated in Condition S-8, they almost always volunteered the information that they were aware that in many lists a word had been repeated. All Ss upon being questioned indicated knowledge of the repetitions. This matter could be reconciled to a trace notion by assuming that, when input arrives at a currently or recently activated logogen, the $S$ is aware that it is a reactivation. It could also be that a counter exists which is independent of the logogen.

The difference found between Condition $A-V$ and Condition N-V indicates that there is a relatively strong association effect present. The addition of an associate of the earlier test item in Position 8 greatly diminishes the improvement in performance obtained by increasing the separation between the two test items. The increase in performance from a one-word separation to a five-word separation is only approximately $5 \%$ when an associate to the earlier test items is in the list, whereas it is over $15 \%$ with no associate.

In contrast to the strong association effect found in Condition $\mathrm{A}-\mathrm{V}$, there is no evidence for an association effect in Condition A-8. When the two words tested are always in Positions 8 and 10, the effect of having an associate of the less recent test item prior to it in the list is at most minimal. 
Table 4

Experiment II: Mean Percent Correct Data

\begin{tabular}{llcccr}
\hline & \multicolumn{3}{c}{ Position of Word Related to Less Recent Test Item } & \multicolumn{2}{c}{ Mean } \\
\cline { 2 - 6 } $\begin{array}{l}\text { Condi- } \\
\text { tion }\end{array}$ & 6 & 4 & 2 & $\mathrm{~N}$ & $(\mathrm{~N}, 2,4,6)$ \\
\hline A-8-F & 47.78 & 50.62 & 61.87 & 65.00 & 56.32 \\
A-8-R & 58.75 & 55.62 & 58.75 & 58.12 & 57.81 \\
Mean & 53.27 & 53.12 & 60.31 & 61.56 & 53.42 \\
\hline
\end{tabular}

The difference between the two associate conditions was unexpected. This difference appeared to be due to a confounding of the order of occurrence in the list of the associate pair. The association to the tested item of the associate pair (the stimulus member) was backwards in both conditions. However, the stimulus member preceded the response member in the list in Condition A.V, while the order was reversed for Condition A-8. Anisfeld and Knapp (1968), using a continuous recognition task in which the $S$ had to indicate if a word had occurred previously, found that only forward association relations showed significant false-positive inducement. It is possible that this asymmetrical relation holds true only for associating to a word that has not occurred previously. A second experiment was designed in order to test this assumption and to provide a better understanding of associational relations.

\section{EXPERIMENT II}

Method

\section{Subjects}

Sixteen students enrolled in an introductory psychology course at the University of Texas at Arlington were used as Ss. Each $S$ participated in two sessions. All Ss received experimental credit toward the course requirement for participating. The restrictions in soliciting the $\mathrm{Ss}$ were the same as in Experiment $\mathbf{I}$.

\section{Design and Stimuli}

The apparatus and stimuli were the same as in Experiment $\mathrm{I}$. Each $S$ received both conditions. Condition A-8-R was the same as Condition A-8 in Experiment I. Condition A-8-F was the same as Condition A-8-R, with the exception that the associates were in forward order in the list. As a result, the response member of the associate pair rather than the stimulus member was the tested item. Associate pairs within the limitations of the available word set were chosen for similarity in frequency of occurrence in the English language (Kucera \& Frances, 1967). Most recent test items were chosen so that they were of intermediate frequency to the two associates, and the list was balanced so that an equal number of Condition A-8-R and Condition A-8-F items were of higher frequency than the more recent item with which they were paired. Otherwise, the design was the same as in Experiment I. The design resulted in a $16 \mathrm{Ss}$ by 2 Conditions by 4 Positions design, with repeated measures on both conditions and positions.

\section{Procedure}

The experimental sessions lasted approximately $1 \mathrm{~h}$. Eighty trials, 40 experimental and 40 control trials, were presented each session. Otherwise, the procedure was the same as in Experiment I.

\section{Results}

The mean percent correct data for Experiment II are shown in Table 4 and Fig. 3. A square-root transformation of the data was made for the purpose of analysis.

An analysis of variance indicated no significant main effects for either factor $[C: F(1,15)=.360 ;$ P: $F(3,45)=2.149, p<.25]$. However, the $C$ by $P$ interaction was significant $[\mathrm{F}(3,45)=3.048, \mathrm{p}<.05]$. Figure 3 indicates that the significant interaction is due to accuracy in Positions 4 and 6 being less than in Positions $\mathrm{N}$ and 2 for Condition A-8-F but not for Condition A-8-R.

\section{Discussion}

The results of Experiment II confirm the importance of direction of association in temporal order judgments. The effect of association is asymmetrical when the less recent test item occurs after its associate in the list. When the association to the earlier test item is forward,

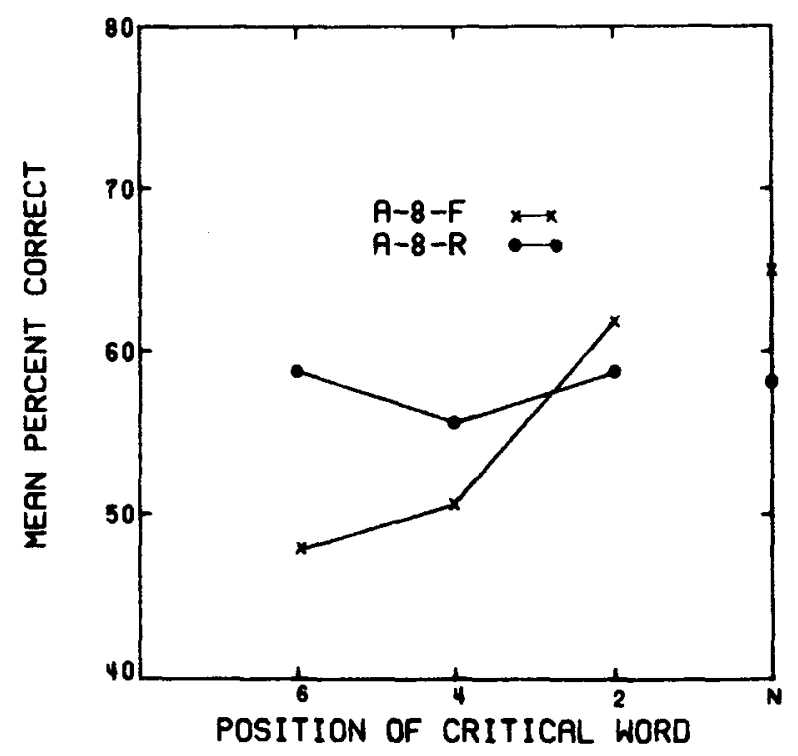

Fig. 3. Mean percent correct recency judgments as a function of position in list and direction of association or word related to less recent test item. 
there is a decrement in percent correct of approximately the same magnitude as that found when the item is repeated. There is no impairment for backward associations to the less recent test item.

\section{CONCLUSIONS}

The results of the experiments support Morton's model of word recognition. The model offers a good explanation of why the association effects were found in two conditions but not in the third. In Condition A-V, although the associate pair occurs in forward order in the list, the association is backwards to the earlier item. In Conditions A-8 and A-8-R, no backward association occurs. The difference appears to be due to whether the stimulus word of the associate pair precedes or follows the response word. When the stimulus word occurs prior to the response word in the list, its threshold is lowered to the point that a much lower association strength (in this case, the backward association) will cause the logogen to "fire" again.

The similarity of the magnitude of the repetition and association effects suggests that the occurrence of a word will almost always cause the logogens of its high associates to make a response available to the output buffer. One implication of this assumption is that performance on a comparative judgment temporal order recognition memory task should be the same if the choice is between two words from the list or one word from the list and a high associate of the other. That is, it is possible that a word will be chosen as if it had been in the list, when it never had.

Alternatively, it may be that a test item will not be chosen as a response if there are no acoustic cues for the word accompanying the semantic cues. It is possible that association effects only the trace of the high associates related to meaning and that an acoustic marker is necessary to indicate that the word actually occurred. Without this marker, the $S$ will realize that the word did not occur.

In general, the present study supports the notion of an associational structure of memory. Future research should clarify the details of the structure.

\section{REFERENCES}

Anisfeld, M., \& Knapp, M. Association, synonymity, and directionality in false recognition. Journal of Experimental Psychology, 1968, 77, 171-178.

Bousfield, W. A., Cohen, B. H., Whitmarsh, G. A., \& Kincaid, W. D. The Connecticut free associational norms: Studies on the mediation of verbal behavior. Technical Report No. 35, November 1961.

Kucera, H., \& Francis, W. W. Computational analysis of present-day American English. Providence, R.I: Brown University Press, 1967.

Morton, J. Repeated items and decay in memory. Psychonomic Science, 1968a, 10, 219-220.

Morton, J. Considerations of grammar and computation in language behavior. Center for Research in Language and Language Behavior, University of Michigan, Progress Report No. 6, May 1968 b.

Morton, J. Interaction of information in word recognition. Psychological Review, 1969, 76, 165-178.

Morton, J. A functional model for memory. In D. A. Norman (Ed.), Models of human memory. New York: Academic Press, 1970. Pp. 203-248.

Palermo, D. S., \& Jenkins, J. J. Word association norms: Grade school through college. Minneapolis: University of Minnesota Press, 1964.

Peterson, L. R., Johnson, S. T., \& Coatney, R. The effect of repeated occurrences on judgments of recency. Journal of Verbal Learning \& Verbal Behavior, 1969, 8, 591-596.

Winer, B. J. Statistical principles in experimental design. Vol. 2. New York: McGraw-Hill, 1971.

Yntema, D. B., \& Trask, F. P. Recall as a search process. Journal of Verbal Learning \& Verbal Behavior, 1963, 2, 65-74.

\section{NOTES}

1. Peterson et al rejected this interpretation from frequency judgment data they collected. However, it is possible that frequency judgments are made independently from the traces used for recency judgments.

2. Position $\mathrm{N}$, which was the same in each condition, was included as a control to insure that group differences were not solely due to differences in the base rate of performance. Because no differences were expected for Position $\mathrm{N}$ between conditions, inclusion of it in the overall analysis of variance would dilute the conditions main effect. Conversely, exclusion of Position $\mathbf{N}$ would dilute the positions main effect. It was concluded that the data for Experiment I could best be represented by omitting Position $\mathrm{N}$ from the analysis of variance.

\section{(Received for publication August 3, 1973;} accepted August 31, 1973.) 